\title{
Exame físico de bovinos prevenidos com acetamida na intoxicação experimental por Palicourea marcgravii
}

Débora Ribeiro de Mendonça”, Ruth Guedes Fagundes Jácome, Carlos Manoel da Silva Borges, Aline Barichello Cerqueira, Beatriz de Aguiar Fernandes Delduque, Milenna Karoline Fernandes Rodrigues, Fabrício Carrião dos Santos, Paulo Henrique Jorge da Cunha

Universidade Federal de Goiás (UFG), Goiânia, GO, Brasil

*Autor correspondente

e-mail: deboraribeirovet@hotmail.com

\section{Resumo}

A Palicourea marcgravii é considerada a principal planta tóxica de interesse pecuário no Brasil. 0 seu princípio tóxico é o monofluoroacetato de sódio (MFA) e causa a morte súbita em bovinos. O quadro clínico inicia-se em torno de seis horas após a ingestão da dose tóxica, caracterizado em geral por pulso venoso positivo, ataxia, tremores musculares, decúbito esterno-abdominal, decúbito lateral, movimentos de pedalagem, convulsão tônica e morte. A acetamida $\left(\mathrm{C}_{2} \mathrm{H}_{5} \mathrm{NO}\right)$ tem sido empregada na prevenção e tratamento de intoxicação pelo MFA, por ser considerada um doador de acetato. 0 objetivo foi avaliar clinicamente bovinos que receberam de forma preventiva acetamida três horas antes da intoxicação experimental por P. marcgravii $(1,8 \mathrm{~g} / \mathrm{kg}$ de PV por via oral). Foram utilizados bovinos da raça Nelore, machos, de seis a 8 meses de idade, desmamados, peso de 110 a $170 \mathrm{~kg}$, divididos em dois grupos experimentais: G1 - seis animais receberam 1g/kg de peso vivo de acetamida, via oral; G2 - seis bovinos receberam $2 \mathrm{~g} / \mathrm{kg}$ de peso vivo de acetamida por via oral. Foram avaliad os a frequência cardíaca (FC), frequência respiratória (FR), movimentos ruminais (MR) e temperatura corporal (ToC) nos momentos da administração da acetamida, da intoxicação e pós intoxicação $(3,9,12,15$, 18, 21, 24, 36, 48, 72 e 96 horas). 0 estudo desenvolvido em delineamento inteiramente casualizado em esquema de parcelas subdivididas no tempo. Os sinais clínicos iniciaram-se entre 12 a 15 horas após a ingestão da planta tóxica e acompanhada de apatia discreta a moderada em todos os animais. Em ambos os grupos notaram-se bovinos com pulso venoso positivo, tremores musculares, decúbito esternal, posição de autoauscultação e severa incoordenação. De forma isolada, observaram-se sinais de sialorreia, midríase e polaquiúria em três animais. A intoxicação causou a morte de um bezerro do G1 e de dois animais do G2. As médias gerais e desvio padrão da FC (G1 - 66,0 \pm 12,7; G2 - 64,8 \pm 18,4), FR (G1 - 19,5 \pm 10,3; G2 - 19,9 \pm 8,1), MR (G1 - 3,8 $\pm 2,6 ; \mathrm{G} 2-3,9 \pm 1,8)$ e T ${ }^{\circ} \mathrm{C}(\mathrm{G} 1-38,6 \pm 0,8 ; \mathrm{G} 2-38,5 \pm 0,9)$ se mantiveram dentro dos parâmetros 
de referência. As médias foram comparadas pelo Teste de Wilcoxon para FC, FR e MR e Teste de Tukey para $\mathrm{T}^{\circ} \mathrm{C}$. A escolha do teste de comparação das médias foi após os testes de normalidade e homocedasticidade das variáveis. As médias dos parâmetros não diferiram $(\mathrm{P}>0,05)$ entre os tratamentos para cada momento e entre os momentos em cada tratamento, exceto pela temperatura corporal. As diferenças verificadas na $\mathrm{T}^{\circ} \mathrm{C}$ provavelmente estão associadas à temperatura ambiente no momento da colheita, uma vez que as maiores $\mathrm{T}^{\circ} \mathrm{C}$ foram percebidas nos períodos mais quentes do dia. A administração da acetamida não impediu o aparecimento dos sinais clínicos, entretanto, estes iniciaram-se mais tardiamente quando comparados aos relatos na literatura. A prevenção foi eficaz ao evitar a morte de $75 \%$ dos animais intoxicados. 